\title{
Identificação de fungos endofíticos em miniestacas de acácia-negra
}

\author{
Izabela Moura Duin"; Thiare Aparecida do Valle Coelho' ${ }^{1}$ Carolina Gracia Poitevin²; Álvaro Figueredo dos Santos ${ }^{3 *}$; \\ Ida Chapaval Pimentel ${ }^{2}$; Celso Garcia Auer ${ }^{3 *}$
}

${ }^{1}$ Programa de Pós-graduação em Engenharia Florestal, Universidade Federal do Paraná, CEP Curitiba, PR, Brasil. ${ }^{2}$ Programa de Pós-graduação em Microbiologia Patologia Básica, Universidade Federal do Paraná, Curitiba, PR, Brasil. ${ }^{3}$ Embrapa Florestas, CP 319, 83411-000, Colombo, PR, Brasil. *Bolsista CNPq.

Autor para correspondência. Celso Garcia Auer (celso.auer@embrapa.br).

Data de chegada: 29/05/2017. Aceito para publicação em: 02/10/2017.

$10.1590 / 0100-5405 / 180656$

\section{RESUMO}

Duin, I.M.; Coelho, T.A.V.; Poitevin, C.G.; Santos, A.F. dos; Pimentel, I.C.; Auer, C.G. Identificação de fungos endofíticos em miniestacas de acácia-negra. Summa Phytopathologica, v.44, n.3, p.278-280, 2018.

Fungos endofíticos podem ter várias relações com mudas de plantas, desde a patogênese até a proteção e estímulo ao crescimento. $\mathrm{O}$ objetivo deste estudo foi isolar e identificar fungos endofíticos em miniestacas de acácia-negra. Miniestacas assintomáticas foram avaliadas e seis espécies de fungos endofíticos foram isoladas e identificadas.

Palavras-chave: Identification of endophytic fungi in black wattle minicuttings

\begin{abstract}
Duin, I.M.; Coelho, T.A.V.; Poitevin, C.G.; Santos, A.F. dos; Pimentel, I.C.; Auer, C.G. Identification of endophytic fungi in black wattle minicuttings. Summa Phytopathologica, v.44, n.3, p.278-280, 2018.
\end{abstract}

Endophytic fungi can have several relationships with seedlings, from pathogenesis to protection and growth stimulus. The aim of the present study was to identify endophytic fungi in minicuttings of black wattle. Asymptomatic minicuttings were evaluated and six species of endophytic fungi were isolated and identified.

Keywords: Acacia mearnsii, vegetative propagation, nursery.

Todos os microrganismos que habitam o interior de um vegetal, ao menos em um período do seu ciclo de vida, podem ser considerados endofíticos ocupando os espaços intercelulares dos tecidos vegetais, como folhas e caules, sem causar danos aparentes (8).

Os microrganismos endofíticos penetram nas plantas basicamente através de aberturas naturais ou ferimentos, sendo que a principal porta de entrada é o sistema radicular (8). Os endofíticos frequentemente induzem alterações morfológicas, fisiológicas e bioquímicas em seus hospedeiros, o que pode afetar a performance das plantas sob diferentes estresses bióticos ou abióticos, tais como déficit hídrico, salinidade e altas concentrações de metais no solo, herbicidas e herbívoros (5). Estes microrganismos podem ser benéficos aos hospedeiros ao conferir resistência a insetos e herbívoros, tolerância à dessecação, proteção contra patógenos e estimular o crescimento (8).

Por essas considerações, um levantamento exploratório de fungos endofíticos em miniestacas de acácia-negra foi desenvolvido para conhecer sua diversidade e as possíveis interações na miniestaquia desta espécie florestal.

A coleta de miniestacas assintomáticas de acácia-negra foi realizada em setembro/2015, em minijardim clonal localizado em viveiro comercial de Triunfo/RS. Cinquenta miniestacas assintomáticas foram coletadas ao acaso na casa de vegetação, embaladas em sacos plásticos limpos, identificadas e levadas ao Laboratório de Patologia Florestal da Embrapa Florestas, Colombo/PR.

Utilizou-se a técnica de isolamento em meio de cultura descrita por Araújo et al. (1), que consta da lavagem das amostras em água corrente, imersão em solução de álcool $70 \%$ por 1 min, imersão em solução de hipoclorito de sódio $1 \%$ por 3 a 4 min, imersão em solução de álcool $70 \%$ por $30 \mathrm{~s}$ e enxágue por duas vezes em água ultrapurificada estéril. As amostras foram fragmentadas com o auxílio de bisturi e os fragmentos, de aproximadamente cinco $\mathrm{mm}$ de comprimento, foram colocados em placas de Petri contendo meio BDA e incubadas em câmara B.O.D a $24 \pm 2{ }^{\circ} \mathrm{C}$, com ausência total de luz, por sete dias. Para a purificação das culturas, foi realizada repicagem para novas placas com meio BDA.

Estruturas reprodutivas foram retiradas de culturas puras e montadas em lâminas coradas com líquido de Amann e por meio da observação microscópica das lâminas foi realizada a identificação dos fungos, ao nível de gênero (2). Para a confirmação das espécies, foi realizado o sequenciamento da região ITS1-5,8S-ITS2 do DNA ribossomal (10) e posterior comparação com sequências depositadas no banco de dados do NCBI (National Center for Biotechnology Information website). O sequenciamento foi realizado no Laboratório de Microbiologia e Biologia Molecular (LABMICRO) da UFPR. As culturas obtidas foram preservadas em tubos inclinados com meio BDA recobertas com óleo mineral e em vidros de penicilina contendo água ultrapurificada estéril 
Tabela 1. Fungos endofíticos identificados em miniestacas assintomáticas de acácia-negra. Setembro/2015, Triunfo/RS.

\begin{tabular}{|c|c|c|c|}
\hline Isolado & Fungo & Acesso GenBank & Identidade (\%) \\
\hline E2 & Papiliotrema fuscus J.P. Samp., J. Inácio, Fonseca \& Fell & KY962980 & 99 \\
\hline E3 & Colletotrichum sp. & KY962997 & 100 \\
\hline E4 & Colletotrichum sp. & KY962998 & 100 \\
\hline E7 & Colletotrichum gloesporioides Penz. & KY962995 & 100 \\
\hline E8 & Colletotrichum gloesporioides Penz. & KY962996 & 100 \\
\hline E9 & Diaporthe sp. & KY962982 & 99 \\
\hline E10 & Diaporthe sp. & KY962983 & 99 \\
\hline E14 & Diaporthe sp. & KY962988 & 99 \\
\hline E15 & Diaporthe inconspicua R.R. Gomes, C. Glienke \& Crous & KY962985 & 99 \\
\hline E16 & Eutypella scoparia Schwein. & KY962999 & 97 \\
\hline E17 & Neopestalotiopsis clavispora (G.F. Atk.) Maharachch., K.D. Hyde \& Crous & KY962989 & 100 \\
\hline E18 & Neopestalotiopsis clavispora (G.F. Atk.) Maharachch., K.D. Hyde \& Crous & KY962990 & 100 \\
\hline E19 & Phoma sp. & KY962991 & 99 \\
\hline E20 & Phoma sp. & KY962992 & 99 \\
\hline E21 & Sporobolomyces carnicolor Yamasaki \& H. Fujii ex Bai \& Boekhout & KY962981 & 100 \\
\hline
\end{tabular}

e lacrado com selo de alumínio (método de Castellani). Os isolados encontram-se depositados na Coleção de Fungos e Oomicetos Florestais da Embrapa Florestas, Colombo/PR.

Vinte e nove fungos endofíticos foram obtidos de miniestacas assintomáticas de acácia-negra: Colletotrichum sp. (7\%), Colletotrichum gloesporioides (14\%), Diaporthe sp. (21\%), Diaporthe inconspicua (3\%), Eutypella scoparia (3\%), Sporobolomyces carnicolor (3\%), Neopestalotiopsis clavispora (7\%), Papiliotrema fuscus (7\%), Phoma sp. (7\%) e não identificados (28\%). Os fungos identificados e respectivas sequências depositadas no GenBank encontramse na Tabela 1. Fungos dos gêneros Colletotrichum, Diaporthe, Neopestalotiopsis e Phoma podem causar doenças em mudas florestais como eucalipto e erva-mate.

Acerca de fungos endofíticos em miniestacas e mudas acácia-negra, não existem trabalhos publicados. $D$. inconspícua foi relatado como endofítico em pecíolos de espinheira-santa (4) e Colletotrichum sp. em folhas de mudas de graviola (7). Do gênero Pestalotiopsis, próximo a $N$. clavispora, Bettucci e Saravay (3) encontraram Pestalotiopsis guepini (Desm.) Stey. em folhas e hastes de mudas de Eucalyptus globulus Labill. e Pestalotiopsis sp. em segmentos de hastes de mudas seminais de Eucalyptus benthamii Maiden \& Cambage (9).

Aspectos como abundância, diversidade e composição de espécies endofíticas podem ser influenciadas por fatores ambientais, como por exemplo a localização geográfica da espécie florestal (6). Como a coleta foi feita em um minijardim clonal, houve pouca variação geográfica que pudesse expressar toda a diversidade de fungos endofíticos presentes em mudas de acácia-negra. Além disso, as coletas foram efetuadas em local onde a maioria das minicepas apresentam pouca ou nenhuma variabilidade genética, fator que também pode restringir o número de espécies fúngicas associadas. Para se ampliar o conhecimento de fungos endofíticos em plantas jovens de acácia-negra, seria recomendado analisar mudas seminais.

\section{AGRADECIMENTOS}

Agradecemos à TANAC S.A. pelo apoio financeiro e técnico, à CAPES pela bolsa do primeiro autor, ao Laboratório de Microbiologia e Biologia Molecular da UFPR e Embrapa Florestas pelo apoio estrutural e técnico.

\section{REFERÊNCIAS}

1. Araújo, W.L.; Lacava, P.T.; Marcon, J.; Lima, A.O.S.; Sobral, J.K.; Pizzirani-Kleiner, A.A.; Azevedo, J.L. Guia prático: isolamento e caracterização de microrganismos endofíticos. Piracicaba: Cooperativa Luiz de Queiroz, 2010. 167p.

2. Barnett, H.L.; Hunter, B.B. Illustrated genera of imperfect fungi. 3rd ed. New York: MacMillan, 1972. 241p.

3. Bettucci, L.; Saravay, M. Endophytic fungi of Eucalyptus globulus: a preliminary study. Mycological Research, Cambridge, v.97, p.679-682, 1993.

4. Gomes, R.R.; Glienke, C.; Videira, S.I.R.; Lombard, L.; Groenewald, J.Z.; Crous, P.W. Diaporthe: a genus of endophytic, saprobic and plant pathogenic fungi. Persoonia, Leiden, v.31, p.1-41, 2013.

5. Gundel, P.E.; Martínez-Ghersal, M.A.; Batista, W.B.; Ghersa, C.M. Dynamics of Neotyphodium endophyte infection in ageing seed pools: incidence of differential viability loss of endophyte, infected seed and non-infected seed. 
Annals of Applied Biology, Wellesbourne, v.156, n.2, p.199-209, 2010.

6. Hoffman, M.T.; Arnold, A.E. Geographic locality and host identity shape fungal endophyte communities in cupressaceous trees. Mycological Research, Cambridge, v.112, p.331- 344, 2008.

7. Oliveira Silva, R.L.; Luz, J.S.; Silveira, E.B.; Cavalcante, U.M.T. Fungos endofíticos em Annona spp.: isolamento, caracterização enzimática e promoção do crescimento em mudas de pinha (Annona squamosa L.). Acta Botânica Brasílica, Brasília, DF, v.20, p.649-655, 2006.

8. Neto, P.A.S.P.; Azevedo, J.L.; Caetano, L.C. Microrganismos endofíticos em plantas: status atual e perspectivas. Boletín Latinoamericano y del Caribe de Plantas Medicinales y Aromáticas, Santiago, v.3, p.69-72, 2004.
9. Sbravatti Junior, J.A.; Auer, C.G.; Pimentel, I.C.; Santos, A.F.; Schultz, B. Seleção in vitro de fungos endofíticos para o controle biológico de Botrytis cinerea em Eucalyptus benthamii. Floresta, Curitiba, v.43, n.1, p.145-152, jan./mar. 2013.

10. White, T.J.; Bruns, T.; Lee, S.; Taylor, J. Amplification and direct sequencing of fungal ribossomal RNA genes for phylogenetics. In: Innis, M.A. PCR protocols: a guide to methods and applications. London: Academic Press, 1990. p.315-322. 